\begin{abstract}
Artículo de Reflexión E15A04. * Una versión previa y más breve de este artículo fue presentada al XXIII Congreso Internacional de Contaduría, Administración e Informática, en la Universidad Nacional Autónoma de México (2018) * Recibido 20.02.2019. * Aceptado versión final: 14.05.2020.

* JEL: M00, M10, M19 * doi: 10.33571/teuken.v12n18a1 * Pp. 25-44
\end{abstract}

\title{
La terminología en administración
}

\section{The terminology in management}

\author{
Luis Antonio Cruz Soto - Martha Julián Peña \\ MÉJICO
}

Resumen: el objetivo del artículo es analizar la situación actual de la terminología en la administración. El problema de investigación se afinca en ofrecer una exploración teórica e histórica en torno al lenguaje administrativo; la metodología consiste en realizar una revisión documental de algunos de los textos más significativos del pensamiento administrativo. Este trabajo se divide en tres apartados: el primero presenta una exploración conceptual sobre la terminología y el lenguaje especializado; en el segundo se examina la situación actual de la terminología administrativa, y finalmente se analizan los términos 'organización' y 'administración' para evidenciar la ambigüedad que padece el lenguaje administrativo. La principal conclusión señala que la terminología administrativa es imprecisa y ambigua, por lo que es necesario aspirar a un lenguaje especializado de la administración claro y preciso.

Palabras clave: terminología administrativa, lenguaje administrativo, administración, lenguaje especializado.

Abstract: this article aims to analyze the situation of terminology in business administration. The research problem is based on offering a theoretical and historical exploration of administrative language since its emergence as a discipline; the methodology consists of carrying out a documentary review of some of the most significant texts of administrative thinking. This work is divided into three sections. The first one carries out a conceptual exploration around terminology and specialized language; the second one examines the current status of administrative terminology; lastly, the terms organization and business administration are analyzed to demonstrate, from themselves, the ambiguity that the administrative language suffers. The main conclusion indicates that administrative terminology is imprecise and ambiguous, so it is necessary to aspire to a clear and precise specialized language for the administrative discipline.

Keywords: administrative terminology, administrative language, management, specialized language.

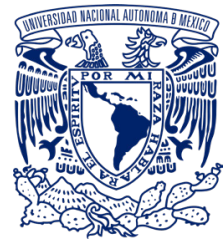

Luis Antonio Cruz Soto es Doctor en Ciencias de las Administración de la Universidad Nacional Autónoma de México, Licenciado en Contaduría y Maestro en Ciencias Sociales. Es Investigador y Profesor en la Facultad de Contaduría y Administración, de la Universidad Nacional Autónoma de México.

Contacto: Icruz13@icloud.com

Orcid: 0000-0002-6540-5792

Teuken Bidikay Vol. 12 № 18 (Medellín, Colombia) • Ene-Jun 2021. ISSN: 2215-8405 - e-ISSN 2619-1822. Pp. 25-44 


\section{A terminologia na administração}

Resumo: o objetivo deste artigo é analisar a situação terminológica na administração. O problema de pesquisa baseia-se em oferecer uma exploração teórica e histórica da linguagem administrativa desde seu surgimento como disciplina; a metodologia consiste em realizar uma revisão documental de alguns dos textos mais significativos do pensamento administrativo. Este trabalho está dividido em três seções: na primeira, uma exploração conceitual é realizada em torno da terminologia e da linguagem especializada; no segundo, examina o status atual da terminologia administrativa; finalmente, no terceiro, os termos organização e administração são analisados para mostrar, a partir desses dois exemplos, a ambigüidade que a linguagem administrativa sofre. A principal conclusão indica que a terminologia administrativa é imprecisa e ambígua, por isso é necessário aspirar a uma linguagem especializada em administração clara e precisa.

Palavras-chave: terminologia administrativa, linguagem administrativa, administração, linguagem especializada

...lo único que haría que su inteligencia fuera capaz de vencer los obstáculos de la supervivencia no estaba en la fuerza de los músculos, en la delicadeza del olfato, el fino oído o la robusta mandíbula, sino en la capacidad de comunicarse, de transmitir a sus descendientes sus conocimientos y su sabiduría, de explicar a los demás miembros de su raza los secretos del mundo...

El futuro de la raza humana estaba en la palabra.

Sobre el mito de Prometeo

\section{Introducción}

E

I objetivo de este artículo es analizar la terminología en administración. Todo concepto que surge del conocimiento disciplinario tiene su repercusión epistemológica en la comprensión teórica o práctica de toda disciplina; por esta razón es importante determinar, en la medida de lo posible, las fronteras terminológicas que existen entre el lenguaje común y el lenguaje científico o especializado. El lenguaje científico o especializado provee de conceptos capaces de interpretar correctamente el conocimiento que se deriva de una disciplina, al margen de lo que pueda decirse, incluso, desde el lenguaje común.

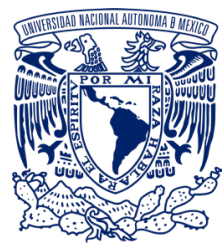

Martha Julián Peña es Licenciada en Literatura Hispánica, Profesora en la Facultad de Contaduría y Administración, de la Universidad Nacional Autónoma de México.

Contacto: mjulian@fca.unam.mx 
Desde el pensamiento administrativo, Herbert Simon (1984, p. XLI) advierte esa debilidad en la teoría de la administración, al no encontrar suficientes conceptos que permitan su desarrollo, lo cual es una de sus principales justificaciones para escribir su principal obra Elcomportamiento administrativo, que a la letra dice:

Este estudio representa una tentativa de construir instrumentos útiles para mi propia investigación en el campo de la Administración [sic] pública ${ }^{1}$. Nació de mi convencimiento de que no poseemos todavía, en este terreno, los instrumentos lingüísticos y de concepto adecuados para describir, de una manera realista y significativa, ni siquiera una sencilla organización administrativa [...]. (Simon, 1984, p. XLI)

Ese autor apunta a la necesidad de contar con conceptos adecuados que sustenten el significado de la administración, lo que habrá de repercutir en una mayor solidez y comprensión en la explicación de los fenómenos administrativos, evitando su vaguedad y relativización terminológica.

La necesaria consolidación de la administración como disciplina apunta a una doble posibilidad desde la lingüística: la de utilizar los conceptos de otras disciplinas de una manera fidedigna y la de sustentar una terminología propia que fundamente su contenido teórico y práctico. Por esta razón se considera que es fundamental que los conceptos que habrán de sostener su explicación deberán corresponder con su precisión. El esfuerzo de Simon se orientó a la necesidad de construir conceptos y darles un contenido lo más exacto posible; la crítica que expresó con respecto a los principios de la administración, por ejemplo, fue una consecuencia de esa ambigüedad y poca claridad en la definición del término 'principio'; por esta razón señaló que antes de que una ciencia pudiera desarrollar principios debía poseer conceptos. (Simon, 1984, p. 36)

La precisión conceptual se puede entender a partir de dos aspectos: uno, como un elemento inherente a la generación de conocimiento teórico, que entraña la delimitación de conceptos determinantes en el discurso científico y, dos, la exactitud con la que se entienden los términos en el campo del saber; por ejemplo, asumir claramente y sin ambigüedades los significados de eficacia, productividad, jerarquía o división del trabajo como términos de la administración. El utilizar estas palabras con un significado en el ámbito propio de la disciplina no necesariamente implica que deben

1 La trascendencia de la obra de Simon no ha sido exclusivamente en el campo de la administración pública, sino que ha sido extensiva a la administración en general. 
emplearse en el mismo sentido en otras disciplinas, cómo sería el caso de la productividad en economía o la división del trabajo en sociología.

\section{La terminología y el lenguaje especializado}

Las palabras expresan el contenido que caracteriza a las cosas; en ello se advierte la necesidad de una precisión lingüística, real e histórica, que permite sustentar el habla y el pensamiento. Los términos hacen posible el diálogo del individuo consigo mismo y con la comunidad, que se manifiesta desde una sencilla comunicación hasta la comprensión de realidades más complejas. Si ya desde el lenguaje común las palabras tienden a la aproximación genuina de la realidad, en el lenguaje especializado o científico esta connotación adquiere una importancia mayor porque significa dar razón de realidades más específicas; por esta razón, la precisión lingüística en el lenguaje científico es una aspiración y una necesidad en el conocimiento disciplinario.

La terminología es una necesidad en el conocimiento de una disciplina; sin la identificación de palabras que le son determinantes para su estudio y comprensión, no sería posible aspirar a una comunicación uniforme entre comunidades especializadas. Para Lara (2006), un léxico de una lengua histórica contiene una cantidad indeterminada e indeterminable de vocablos; advierte que esta indeterminación se debe a que "las palabras se relacionan directamente con la experiencia del mundo y de la vida que, por naturaleza, varían en el tiempo y en el espacio y depende de la novedad en cada experiencia humana socialmente compartida" (p. 147). Lara se refiere al léxico de una lengua en general, pero su explicación sirve para el propósito de un léxico de una lengua especializada, en el hecho de integrar palabras que definen a una disciplina y que la caracterizan; se trata de palabras compartidas en una comunidad especializada que son determinantes para la explicación de los temas que le son propios.

Si bien la referencia terminológica de una disciplina es un proceso en continua revisión, existen palabras propias de su bagaje conceptual que son determinantes para definirla y aspirar a una solidez de sus significados, así como para manifestar esencias de realidades que le son propias. Una disciplina es ello, en buena medida, por la integración de una terminología.

Si bien el lenguaje común puede ser una fuente importante para ese propósito, este se convierte en una limitante a medida que las disciplinas experimentan un mayor desarrollo, debido a queya no es posible definir con exactitud contenidos específicos con la precisión que requiere un lenguaje especializado; incluso, como lo advierte Gutiérrez (1998, p. 25), puede 
resultar que este lenguaje común represente un obstáculo para la solución de los problemas propios de la disciplina, debido a que la existencia de una mala terminología puede obligar a cambiar erróneamente conceptos y a buscar explicaciones forzadamente. La validez en la utilización de palabras propias de un lenguaje especializado está dada por el fundamento de los contenidos que son propios de una disciplina.

Indudablemente, existen claras diferencias entre las palabras usuales del lenguaje ordinario y los elementos que componen una terminología; las primeras responden a la visión que de la realidad se ha formado cada cultura; mientras que la terminología no constituye campos léxicos, no organizan significados lingüísticos sino fenómenos definidos por las ciencias y las técnicas, [que] no constituyen estructuraciones semánticas sino clasificaciones objetivas. (Julián, 1997, pp. 2-3)

La terminología refiere a objetos de conocimiento en campos del saber especializados; la integración de términos que son característicos de una disciplina sustenta objetos de estudio, lo que define campos de conocimiento. La definición terminológica precisa es una cualidad que determina un lenguaje especializado; aún reconociendo que las palabras ofrezcan una variedad de acepciones en este campo, prevalece el criterio de la exactitud en los contenidos de las palabras.

El lenguaje especializado define una ciencia porque logra integrar una terminología propia que habrá de servir para comunicar su ámbito de significado técnico, de ahí la importancia de apelar a una unificación terminológica en la que se reconozca un contenido conceptual común entre sus especialistas. Benveniste (1987) señala lo siguiente:

La constitución de una terminología propia marca en toda ciencia el advenimiento o el desenvolvimiento de una conceptualización nueva, y con ello señala un momento decisivo de su historia. Hasta podría decirse que la historia propia de una ciencia se resume en la de los términos que le son propios. Una ciencia no comienza a existir ni puede imponerse más que en la medida en que hace existir o impone sus conceptos en su denominación. No tiene otro modo de establecer su legitimidad sino especificar, denominándolo, su objeto, que puede ser un orden, un dominio nuevo o un modo nuevo de relación entre ciertos datos. El instrumental de la mente consiste primero en un inventario de términos que enumeran, configuran o analizan la realidad. (p. 249)

La importancia de integrar términos propios en una ciencia significa denominar, es decir, crear conceptos (Benveniste, 1987, p. 249), lo que es una de las principales cualidades de las ciencias. La terminología sugiere un lenguaje científico, lo que se entiende como: 
todo mecanismo utilizado para la comunicación cuyo tema tenga que ver con cualquier ámbito de la ciencia, ya se produzca esta comunicación exclusivamente entre especialistas o entre ellos y el gran público, sea cual sea la situación en que esa comunicación se produce y el canal -oral o escrito- elegido para establecerla.

(Gutiérrez, 1998, p. 22)

El lenguaje científico no solo refiere a un ámbito de comunicación entre especialistas, sino que es una relación comunicativa de una ciencia con todo el público, de modo que este lenguaje constituye un espacio de interpretación y comprensión propio que no es igual al que se utiliza en el lenguaje común y en el lenguaje de otras disciplinas. Al asumir un lenguaje científico queda plenamente identificado un campo del saber; por esta razón, los términos que emplea relacionan, lo más estrechamente posible, los hechos que le son propios con sus conceptos.

La característica principal que define el contenido del lenguaje especializado es la precisión; esto implica supeditar la interpretación al significado con la mayor exactitud posible, de manera que el contenido conceptual sea lo más cercano a la realidad que se intenta designar. Gutiérrez (1998, p. 23) señala que la precisión terminológica establece que el significado de los términos no se encuentra condicionado por los elementos que intervienen en el acto comunicativo: el emisor del mensaje, el receptor o el contexto; para esta autora, esa posibilidad únicamente se logra mientras el significado está previamente delimitado.

Condicionar un vocablo especializado al emisor del mensaje, al receptor o al contexto significa incorporar interpretaciones que impiden la fluidez en la comunicación entre los especialistas y del especialista con el público. Mediante la terminología, los miembros que forman parte de un campo de conocimiento habrán de tener la similitud de significados de los temas que les son propios $y$, como consecuencia, los términos serán menos comprensibles para la gente común o los miembros de otras disciplinas.

\section{La terminología administrativa}

El lenguaje de la administración refiere a una terminología y a la construcción de sus conceptos; no solo se trata de una necesidad lingüística para dar solidez teórica a la administración, sino que es una justificación imprescindible en la construcción de toda la disciplina, incluyendo su carácter técnico, de manera que sirva para alcanzar la univocidad en la comprensión de las palabras fundamentales que emplea. La aspiración de un lenguaje especializado, como es el de la administración, es procurar la erradicación de la ambigüedad y la imprecisión, lo que implica, por un lado, la identificación de sus términos fundamentales y, por el otro, la construcción clara y precisa de sus conceptos. 
Chester Barnard (1960) y Herbert Simon (1988) advierten esta necesidad de la administración en sus obras principales: Las funciones del ejecutivo y El comportamiento administrativo, respectivamente. Ambos autores exponen la necesidad de fortalecer el lenguaje administrativo, capaz de aspirar a una mejor comprensión de sus conceptos disciplinarios y lograr una comunicación más clara entre sus especialistas. Los motivos de Barnard y Simon, al escribir sus respectivas obras, así lo demuestran. Barnard (1960) los expone de la siguiente manera:

Muchas veces he notado que los ejecutivos pueden entenderse entre sí con pocas palabras cuando discuten problemas esenciales de la organización, siempre que estas cuestiones no dependan de las tecnologías ${ }^{2}$ de sus respectivos campos. Esto es sorprendentemente cierto: se observa, de hecho, principalmente, cuando hombres de campos diametralmente diferentes discuten estas cuestiones. No se trata de una nomenclatura común o un estudio general de los sistemas organizacionales. Hasta hace poco tiempo, ha habido poca literatura que pudiera servir como una base común de comprensión, desconocida y con escaso interés en la mayor parte de los ejecutivos. Además, si estas cuestiones son consideradas noúnicamente como prácticos, sino como problemas teóricos, la comprensión de estos temas parece invariablemente a desaparecer tan pronto como la discusión es reemplazada como parte de sus respectivas tecnologías. (pp. vii-viii)

Barnard parece reconocer que no hay una terminología común para hablar de cuestiones propias de las organizaciones, lo que no necesariamente puede ser un problema para la comunicación que se establece entre los ejecutivos; sin embargo, el problema estriba en el campo disciplinar, al no tener una comprensión unificada de los términos que son propios de la disciplina administrativa, por lo que se trata de un problema más de carácter teórico.

Por su parte, la principal justificación que ofrece Simon (1988, p. XLII) para escribir su obra El comportamiento administrativo aparece en el "Prefacio a la primera edición norteamericana", al decir lo siguiente en sus primeras líneas:

Este estudio representa una tentativa de construir instrumentos útiles para mi propia investigación en el campo de la Administración pública ${ }^{3}$. Nació de mi convencimiento de que no

2 Barnard se refiere a estas "tecnologías" como ese campo de estudio particular de las organizaciones.

3 A lo largo de toda su obra se puede advertir que Simon no hace alusión exclusivamente a la administración pública, sino a la administración en general; si acaso el propósito de su libro fue explorar la primera, sus explicaciones sirven como un referente teórico de toda la disciplina administrativa. 
poseemos todavía, en este terreno, los instrumentos lingüísticos y de concepto adecuados para describir, de manera realista y significativa, ni siquiera una sencilla organización administrativa; es decir, para describir de una manera que nos proporcione la base para un análisis científico de la eficacia de su estructura y funcionamiento (Simon, 1988, p. XLII).

Simon identifica dos problemas fundamentales en la disciplina administrativa: la carencia de instrumentos lingüísticos y sus conceptos; para este autor, no existe una terminología que permita entender el significado de la organización a través de la administración y tampoco es posible la identificación de una conceptualización clara. Esta misma limitante la comparte Barnard (1988):

Corresponde hacer aquí dos observaciones generales. Una es que toda organización dispone de un lenguaje organizativo propio, y es preciso aprender su uso y significado. La otra es que el comportamiento adolece, a menudo, de falta de coherencia en el lenguaje empleado para describirlo. (p. XL)

Si bien existe un avance significativo en la construcción de una terminología administrativa y en la precisión de sus conceptos después de que Barnard y Simon escribieron sus respectivas obras, éste ha sido insuficiente; por ejemplo, actualmente no es posible identificar con toda claridad el significado de la administración y su objeto de estudio, así como términos tan importantes como organización, autoridad, poder, trabajo, liderazgo, entre muchos otros.

Es necesario apelar a una terminología de la administración que permita identificar su propio lenguaje; el propio avance de la disciplina y su consolidación como un ámbito de estudio particular así lo sugieren. Aún falta por construir conceptos precisos y unívocos de los términos que son fundamentales para lograr una mejor comprensión entre sus especialistas y de ellos con el público en general. Así como la solidez disciplinaria se encuentra estrechamente vinculada con la construcción de un lenguaje especializado, la identificación clara de su terminología es una necesidad para la comprensión de las palabras que emplea la disciplina y los campos de estudio que le son propios, como lo indica a continuación Tannenbaum (citado por Jorge Ríos, 2011):

Mi impresión personal es que aún encaramos problemas importantes en lo que respecta a la semántica. En verdad tuvimos gran dificultad para realmente entendernos uno al otro. Como especialistas, usamos terminología muy diferente. Aquí hay solo unos cuantos, sospecho, que tienen siquiera alguna familiaridad con muchos de los términos especializados que son empelados frecuentemente por otros de nosotros en nuestros diferentes 
campos de especialización. (...) Las grabadoras reportan que nuestras dificultades terminológicas se extendieron en muchas direcciones. Se presentaron en el diálogo entre científicos: teóricos de las decisiones con científicos del comportamiento, académicos de sistemas con funcionalistas, y así sucesivamente; enfrentamos grandes dificultades al hablar a través de nuestras especialidades científicas. (p. 65)

El problema de la semántica en la administración tiene repercusiones importantes tanto en la práctica como en la teoría, pero es más notorio en esta última porque tiene implicaciones en la explicación de la realidad administrativa y organizacional. Para Barnard, el problema de la conceptualización incide tanto en la práctica como en la explicación de la administración; indica que la utilidad que tienen los conocimientos más generales en los directivos de una organización procede de la comprensión racional del comportamiento, que está basado en la experiencia: "su valor práctico último es grande, porque agudiza la observación, evita el olvido de factores importantes, proporciona las ventajas de un lenguaje más general y reduce la incoherencia entre el comportamiento y su descripción verbal". (Barnard, 1988, p. XLI).

Al incorporar conceptos en la administración, se procura explicar regularidades de comportamiento y sus posibles causas, lo que resulta útil para la práctica administrativa y define la teoría en la administración.

Antes que una ciencia pueda desarrollar principios debe poseer conceptos. Antes de formular una ley de gravitación fue preciso disponer de las nociones de "aceleración" $y$ "peso". La primera tarea de la teoría administrativa consiste en desarrollar una serie de conceptos que le permita describir las situaciones administrativas en términos aplicables a la teoría. (Simon, 1988, p. 36)

El hecho de que una disciplina con perspectivas teóricas, como es la administración, carezca de un aparato lingüístico uniforme y claro cancela la posibilidad de construir su propio fundamento, de identificar los términos que justifican su existencia, de establecer conceptos precisos y claros y de aspirar a una comprensión unificada entre sus especialistas. Koontz et al. (1988) señalan que "la falta de una clara comprensión de los conceptos, principios y técnicas de la administración dificulta el análisis del trabajo y la preparación de los administradores". (p. 12)

El desarrollo de toda disciplina es una consecuencia del lenguaje especializado que emplea, como se puede observar en disciplinas consolidadas como la sociología, la política, la economía o la antropología, por citar algunas; en estas, el elemento común es la identificación concreta de sus términos y su interpretación más o menos precisa, por lo menos entre los miembros de su comunidad especializada. 
Si bien en la administración puede identificarse una terminología, aún no hay claridad en su integración y, mucho menos, en su precisión conceptual, como bien lo refiere Harold Koontz (2000):

Uno de los grandes obstáculos para desenredar la jungla ha sido
desde hace mucho, y todavía lo es, el problema de la semántica.
Quienes escriben y enseñan sobre administración y campos
relacionados han tendido a usar términos comunes de diferentes
maneras, lo cual es ejemplificado por la variedad de significados
que se han dado a términos tales como "organización", "línea y
staff", "autoridad", "responsabilidad" y "políticas", por mencionar
sólo unos cuantos. [...] en verdad parece que podemos estar
caminando en la dirección necesaria para el desarrollo de una
ciencia - hacia la aceptación de definiciones claras de términos y
conceptos claves. (p. 73)

La teoría de la administración aún no transita hacia la precisión de significados. El principal problema estriba en ofrecer significados del lenguaje común para un lenguaje especializado e incluir diversas acepciones para un mismo término, que en ocasiones difieren sustancialmente. Terry $(1982$, p. 30) señala que no existe una terminología que tenga un amplio reconocimiento y que se use en el campo de la administración; advierte que esto es un problema en la administración porque implica la utilización de distintos términos para referirse a un solo fenómeno, o bien que un solo término se emplee para explicar diferentes situaciones.

A estos problemas de imprecisión en la utilización de los términos en la administración, se pueden añadir otras confusiones en el propio desarrollo del pensamiento administrativo, como son: la confusión entre la práctica y la teoría administrativa; el suponer que se habla de la teoría administrativa cuando se están planteando problemas de funcionamiento o de eficiencia en las organizaciones (por ejemplo, administración científica o principios de la administración); el uso indiscriminado de términos sin tener una comprensión clara de su significado (por ejemplo, liderazgo); la consulta de libros de texto que resumen y hacen una interpretación del pensamiento de los autores clásicos de la administración (por ejemplo, gran cantidad de manuales en los que se compila la interpretación de todo el pensamiento administrativo); la continua utilización de términos que se definen por las modas administrativas y no a partir de hechos sustanciales que delimitan la realidad administrativa (por ejemplo, coaching ontológico, administración por objetivos, administración del conocimiento $\mathrm{u}$ organizaciones que aprenden); el empleo de vocablos para ocultar un trasfondo ideológico (por ejemplo, recursos humanos o capital humano, o la maquinización del trabajo productivo como sinónimo de productividad para alcanzar la competitividad), o el carácter 
superficial con el que se trata de describir hechos de gran complejidad en la administración (por ejemplo, trabajo o cultura).

Todos estos elementos contribuyen a impedir el desarrollo de la disciplina administrativa y la construcción de una terminología consolidada que haga posible aspirar a una teoría administrativa más sólida.

\section{La ambigüedad en la terminología administrativa: los conceptos de administración y organización}

Existe una gran cantidad de palabras en el uso de la disciplina administrativa que resultan imprecisas, poco claras, sin solidez conceptual y que no tienen un significado unívoco, como son los propios términos 'administración' y 'organización'; incluso ambas palabras se han llegado a considerar como sinónimas debido, fundamentalmente, a que una actividad importante que implica la función de administrar se refiere, precisamente a la de organizar ${ }^{4}$.

Carlos Dávila (1985, p. 5) indica que existe una tendencia a utilizar estos dos términos de manera ambigua e imprecisa, lo cual ha conducido, usualmente, a que la administración y la organización sean entendidos como si significaran lo mismo; sin duda, ambos términos se refieren a diferentes cuestiones, pero aún no es posible identificar una conceptualización lo suficientemente sólida para distinguirlos y definirlos con toda precisión.

Sobre el término organización, Simon (1988, p. XV) señala que la mala interpretación de este vocablo constituye una dificultad y genera una resistencia a analizar los factores organizativos del comportamiento administrativo. Por su parte, Ríos (2011, p. 62) realiza un análisis comparativo de las diferentes acepciones de este vocablo en la administración y distingue por lo menos tres significados: primero, se ha entendido como estructuras de funcionamiento administrativo, como son las organizaciones de tipo matricial, vertical, lineal, geográfica o delgada; en un sentido similar, Minztberg (1991, p. 127) había sugerido otro tipo de configuraciones organizacionales, de acuerdo con los objetivos y las actividades que desarrolla cada ente, entre las que se pueden mencionar organizaciones de tipo emprendedor, maquinal, diversificada, profesional o innovadora.

4 Un ejemplo de esta confusión entre organización y administración se puede encontrar en el libro de Luther Gulick et al (1970), particularmente en los tres primeros capítulos. 
En segundo lugar, también la organización se ha interpretado como un ente, tal como lo sugieren Barnard (1960) y Simon (1984), por ejemplo: una empresa, la Iglesia, un gobierno, una universidad, un partido político. Barnard (1960, p. 65) define una organización como un sistema de cooperación de dos o más personas con un fin definido; clasifica a las organizaciones por su funcionalidad u objetivo, tales como las iglesias, los partidos políticos, las asociaciones con fines de fraternidad, el ejército, las empresas industriales, las universidades o las familias.

Mientras que Simon (1984) define a la organización como un "complejo diseño de comunicaciones y demás relaciones existentes dentro de un grupo de seres humanos" (p.XV); señala que la organización es importante porque es donde los hombres pasan la mayor parte de su vida adulta y representa un medio ambiente en el que los seres humanos moldean y desarrollan sus cualidades y hábitos personales.

El tercer significado de organización que resalta Ríos (2011, p. 62) es el que la ha entendido como un ámbito de funcionamiento en el que diferentes departamentos se relacionan, delimitan sus actividades y establecen una jerarquía y línea de mando; este esquema funcional se plasma en manuales de organización y procedimientos y se representa gráficamente en organigramas. En este sentido, Luther Gulick et al. (1970) entienden la "teoría de la organización" como la explicación de:

la estructura de la coordinación que es indispensable entre las distintas unidades de una empresa que aparecen como consecuencia de la división del trabajo. En consecuencia, no es posible decidir cómo debe organizarse una actividad sin tomar en cuenta la manera cómo se va a dividir el trabajo. (p. 6)

Para esos autores, una teoría de la organización es la explicación de la forma en que se distribuye el trabajo, lo que también podría entenderse como el significado de la administración. Asimismo, Fayol (1971) deriva una acepción adicional del término organización en sus 'elementos de la administración': "organizar una empresa es proveerla de todo lo que es útil para su funcionamiento: materias, herramientas, capital y personal" (p. 200); se trata de una concepción que se deriva del verbo organizar, es decir, ordenar o disponer de personas o cosas para el cumplimiento de un objetivo organizacional.

Las diversas acepciones del término organización que se han señalado tienen, por lo menos, cinco diferentes significados. Estos ejemplos en la interpretación de este término evidencian la falta de unificación en su comprensión en el lenguaje administrativo, lo que deriva en un problema de imprecisión; esto impide una comprensión clara y un análisis preciso 
en la disciplina administrativa, tanto en su explicación teórica como en su aplicación práctica.

Este mismo problema de imprecisión en la utilización de los términos se puede encontrar en la palabra administración que se utiliza en esta misma disciplina. Ambas palabras, organización y administración, son fundamentales en el lenguaje administrativo por lo que resulta una preocupación mayor el que no tengan un concepto preciso, claro y unívoco.

Kliksberg (1990) realiza un análisis exhaustivo en torno al término administración; si bien inicia la exploración del concepto a partir de un método erróneo que comúnmente se emplea en la comunidad especializada, como es la consulta de definiciones del diccionario de uso general, realiza un análisis relevante del contenido semántico del vocablo cuando se tratan de incorporar definiciones generales de las palabras en la discusión especializada.

La utilización de diccionarios de la lengua para definir a la administración implica un problema de precisión, tanto en su conceptualización como en la identificación de una interpretación unívoca. Como bien señala Kliksberg (1990, p. 7), el diccionario de uso común no ofrece una perspectiva precisa, clara y objetiva del significado de los términos cuando se trata de conceptualizar vocablos del lenguaje técnico, como sucede con la administración y la organización, de ahí la importancia de explorar su sentido semántico entre la comunidad especializada.

Para ese autor, la elucidación del concepto administración permitirá cumplir dos finalidades: en primer término, aspirar a la precisión del significado de uno de los vocablos centrales del léxico en la disciplina; $y$, en segundo, permitirá una primera delimitación del ámbito de estudio de la disciplina. Ambos objetivos son muy importantes porque habrán de configurar e identificar el objeto de estudio de la administración y proporcionará "un criterio para las temáticas y autores que deben ser considerados parte de ella, e idénticamente los no pertinentes. [Y] nos permitirá así delimitar el campo bibliográfico incluible dentro de este análisis de la evolución doctrinal de la administración". (Kliksberg, 1990, p. 7).

La idea es sustentar el campo de estudio, y la claridad y la precisión terminológica son un camino inevitable para alcanzar ese propósito. Con este fin, Kliskberg (1990, p. 7) propone una segunda instancia de precisión semántica de la palabra administración, que es la de revisar las definiciones que han dado los autores en este campo; sin embargo, las definiciones que se ofrecen desde el pensamiento administrativo son conceptos heterogéneos [...], como puede observarse en la Tabla 1, que 
da una idea precisa de esta gran variedad de perspectivas en torno al significado de la administración.

A juicio de Kliksberg (1990, pp. 8 y 9), esas definiciones agregan una confusión adicional de carácter epistemológico, al postular que se trata de una ciencia (en Taylor), una doctrina administrativa y un arte (en Fayol), una sistematización de prácticas (en Thompson). Para Kliksberg, los intentos de definición posteriores a las de los primeros autores de importancia en administración no aclaran mayormente el problema.

Tabla 1. Definiciones de administración

\begin{tabular}{|c|c|}
\hline AUTOR & DEFINICIÓN \\
\hline $\begin{array}{l}\text { Henri Fayol } \\
(1971, \text { p. } 138 \text { y } 139)\end{array}$ & $\begin{array}{l}\text { Administrar es prever, organizar, dirigir, coordinar, con- } \\
\text { trolar. }\end{array}$ \\
\hline Lyndall Urwick* & $\begin{array}{l}\text { Define la racionalización (sinónimo de administración) } \\
\text { como una actitud y un proceso: como actitud recoge la } \\
\text { creencia de que es posible y deseable realizar un control } \\
\text { más racional de la vida económica del mundo mediante } \\
\text { la aplicación de métodos científicos. }\end{array}$ \\
\hline Olivier Sheldon* & $\begin{array}{l}\text { La administración es la función industrial que se relacio- } \\
\text { na con la determinación de un conjunto de políticas, la } \\
\text { coordinación de finanzas, producción y distribución, el } \\
\text { establecimiento del ritmo de la organización y, por últi- } \\
\text { mo, el control de los ejecutivos. }\end{array}$ \\
\hline $\begin{array}{l}\text { Harold Koontz } \\
\text { y Cyril O'Donnell* }\end{array}$ & $\begin{array}{l}\text { "[...] su labor consiste en realizar cosas por medio de las } \\
\text { personas"; y consideran a la dirección como "un sistema } \\
\text { ideológico de principios". }\end{array}$ \\
\hline Luther Gulick* & $\begin{array}{l}\text { La ciencia de la administración es el conjunto de conoci- } \\
\text { mientos que permiten a los hombres entender las rela- } \\
\text { ciones, predecir los resultados e influir los objetivos de } \\
\text { cualquier situación en la que varios o muchos hombres } \\
\text { se encuentran organizados para trabajar juntos con un } \\
\text { propósito común. }\end{array}$ \\
\hline William Newman* & $\begin{array}{l}\text { La dirección es la guía, conducción y control de los es- } \\
\text { fuerzos de un grupo de individuos hacia algún objetivo } \\
\text { común. }\end{array}$ \\
\hline $\begin{array}{l}\text { Herbert Simon } \\
(1988, \text { p. } 3)^{5}\end{array}$ & $\begin{array}{l}\text { La administración se define ordinariamente como el arte } \\
\text { de conseguir que se hagan las cosas. }\end{array}$ \\
\hline
\end{tabular}

5 Simon propone la definición que se ha dado por otros; él no ofrece una definición de administración. 


\begin{tabular}{|c|c|}
\hline AUTOR & DEFINICIÓN \\
\hline Arthur Thompson* & $\begin{array}{l}\text { La administración tiende a correlacionar y sistematizar } \\
\text { todo lo mejor de las mejores prácticas modernamente } \\
\text { desarrolladas sobre administración febril, y a propugnar } \\
\text { cualquier futuro desarrollo de acuerdo a [sic] los princi- } \\
\text { pios descubiertos }\end{array}$ \\
\hline $\begin{array}{r}\text { George Terry } \\
(1982, \text { p. 20) }\end{array}$ & $\begin{array}{l}\text { La administración es un proceso distintivo que consiste } \\
\text { en planear, organizar, ejecutar y controlar, desempeña- } \\
\text { do para determinar y lograr los objetivos manifestados, } \\
\text { mediante el uso de seres humanos y de otros recursos. }\end{array}$ \\
\hline
\end{tabular}

Nota: Se toman únicamente a los autores que definieron el término administración.

* Estas definiciones fueron tomadas de Kliksberg (1990, pp. 9-10).

Fuente: Elaboración propia

Esta colección de definiciones que ofrecen autores fundamentales en el pensamiento administrativo es una muestra de los problemas a los que se enfrenta la disciplina para definir con claridad la administración y, por correspondencia, identificar con precisión su propio objeto de estudio. Como bien lo señala Kliskberg (1990, p. 11), estos intentos de definición no permiten reconocer con claridad el contenido preciso del término. También así lo advierte Terry (1982):

Laadministración se define de varias formas, dependiendo del punto de vista, convicciones y comprensión del que la define. Por ejemplo, algunos definen a la administración como "la fuerza que dirige un negocio y que es responsable de su éxito o fracaso". Otros afirman que "la administración es el desempeño para concebir y lograr los resultados deseados por medio de los esfuerzos de un grupo, que consisten en la utilización del talento humano y los recursos". Todavía otros, declaran que la administración es sencillamente "lograr que se hagan las cosas mediante la gente", en tanto que otros alegan que puede resumirse en "planeación y ejecución". Una definición adicional es "la administración, [sic] es la satisfacción de necesidades económicas y sociales, siendo productivo para el ser humano, para la economía y la sociedad". Algunos manifiestan, "la administración es un recurso que usan todos para alcanzar los objetivos". Todas estas definiciones tienen su mérito: señalan importantes aspectos de la administración. (p. 20)

Los dos cuestionamientos que se derivan de esta interpretación de Terry y de las definiciones citadas son, por un lado, la falta de comprensión del vocablo y, por el otro, la confusión con el término dirección, que incluso ha llevado a que el propio nombre de la disciplina se pueda llamar indistintamente como administración, gestión, dirección, gerencia o management (Ríos, 2011, p. 37) sin reparar en los problemas de identificación e interpretación que ocasiona esta sinonimia. 
Si es visible este problema en el concepto más importante de la disciplina, administración, los demás términos que le son sustanciales para entender su razón de ser dejan ver aún más la falta de comprensión de sus conceptos. La idea de una terminología administrativa no depende, como lo señala Terry en la cita anterior, del punto de vista y las convicciones, sino de ofrecer certezas lingüísticas que aspiren a la precisión, claridad y univocidad de sus definiciones.

Un ejemplo en la administración de cómo el empleo de términos o tecnicismos no del todo afortunados puede propiciar la tergiversación de conceptos, lo encontramos en el caso del inadecuado rebautizo del concepto funciones de la administración o funciones del administrador como proceso administrativo, a manera de sinónimo, y el empleo inapropiado del término etapas para referirse a los elementos, caso que ha propiciado una grave malinterpretación, por lo menos en nuestro país, de esta noción básica de la teoría administrativa. (Ríos, 2011, p. 14)

El principal problema es dar un contenido práctico y simplificado del significado del saber administrar a un saber que originalmente es explicativo ${ }^{6}$. Este ejemplo de confusión e imprecisión de conceptos fundamentales de la administración es una muestra de las dificultades que existen en el lenguaje administrativo, por lo menos en dos vertientes: por un lado, el forzar la interpretación de una explicación propiamente teórica - como lo sugiere Fayol al exponer los elementos de la administracióna una aplicación práctica - como etapas de un supuesto proceso administrativo-; por otro lado, el tratar de simplificar la explicación administrativa de hechos de gran complejidad'; esta simplificación en la interpretación corre el riesgo de comprender parcialmente la realidad, como bien lo indica Kliksberg: "[...] la realidad no se da dividida, sino formando una unidad y un continuo, y toda escisión conceptual corre el riesgo de deformarla, al simplificarla excesivamente". (1990, p. 41)

Para Koontz, el tener una gran cantidad de escritos acerca de la administración y el que los expertos utilicen el vocablo administración para designar todo lo que se "halla bajo el sol" ¿puede acaso esperarse que

6 Fayol (1971; primera parte, capítulo 1 y segunda parte, capítulo 2), de quien se ha malinterpretado la idea de los elementos de la administración, nunca se refirió a un proceso administrativo, sino que procuró sugerir una definición de la administración, a partir de sus cinco elementos: prever, organizar, dirigir, coordinary controlar. Puede consultarse su obra en el idioma original Administration industrielle et générale. Prévoyance, Organisation, Commandement, Coordination, Controle.

7 Este problema de la simplificación en la explicación y hechos administrativos también se pueden consultar en Simon (1984, p. XXI y siguientes y capítulo II); Aktouf (2009, Introducción), Mintzberg (1991, p. primera y tercera parte). 
la teoría de la administración sea muy útil o científica? La construcción de una teoría o ciencia de la administración aspiraría a procurar la unificación en la comprensión de todos sus vocablos determinantes y "definir el campo de conocimiento específico de administración" (Koontz, citado por Kliksberg, 1990, p. 11).

Y al igual que sucede en la teoría, la técnica aspiraría a tener esas mismas condiciones para comprender los aspectos prácticos que necesita la disciplina para poder actuar en las organizaciones y aspirar a una administración más eficiente. En esta perspectiva, también sería preciso aspirar a una distinción entre la teoría y la técnica administrativa.

[...] el término 'administración' está lejos de tener un significado estándar, aun cuando la mayoría de los estudiosos están de acuerdo en que al menos implica lograr que se hagan las cosas mediante y con personas, pero ¿qué significa ocuparse de todas las relaciones humanas? ¿Un vendedor callejero es un administrador? ¿Un padre es un administrador? ¿El líder de una multitud desorganizada es un administrador? ¿lguala el campo de la administración a los campos de la sociología y de la psicología social combinados? ¿Es el equivalente del sistema entero o de relaciones sociales? (Koontz, 1999, p. 47)

Se trata de una gran variedad de interpretaciones que son el producto de una definición deficiente del término. Lo que aspira una conceptualización del vocablo administración y de los términos determinantes en la disciplina es, precisamente, a disminuir esa vaguedad e interpretación, como una forma de unificar los criterios de comprensión de sus vocablos. Para que un área de conocimientos, como señala Koontz (1999),

no se atasque en un atolladero de malentendidos, la primera necesidad que se tiene es la de una definición del campo, mas no en líneas precisas, detalladas e inflexibles, sino más bien de acuerdo con líneas que le den un contenido razonablemente específico. (pp. 49-50)

No se trata de estandarizar con criterios inflexibles que no abonan a la precisión conceptual de los términos, sino a darle claridad a su contenido para aspirar a una mayor solidez el campo de conocimiento de la administración.

\section{Conclusión}

El reconocer un lenguaje especializado implica asumir una terminología en un campo del saber y procurar un contenido conceptual acorde con este. Si bien se puede decir que es posible identificar un lenguaje propio de la administración, aún no hay suficiente claridad para advertir una 
terminología precisa que permita reconocer las palabras fundamentales que definen a la administración; asimismo, tampoco es posible asumir con solidez los conceptos que se derivan de su terminología, como se ha podido observar en este artículo.

Las imprecisiones en el uso de los términos en la administración, como se ha advertido, exigen la identificación precisa de una terminología y la conceptualización de sus palabras fundamentales con un mayor rigor; la distinción de los términos fundamentales y su conceptualización en el campo de la administración es un elemento de primera importancia para definir sus objetos de estudio.

La limitante lingüística en el campo de la administración, que se ha advertido en este artículo, es una razón de primer orden para aspirar a una claridad en el uso de la terminología administrativa. En esta tesitura, se podría mencionar la posibilidad de un vocabulario especializado propio de la lengua hispánica (Lara, 1994, p. 9) ${ }^{8}$.

El pasar desapercibida esta posibilidad genera una problemática adicional como es la dependencia lingüística de una disciplina a un idioma en particular, como lo señala a continuación Lara (1994) "el sometimiento intelectual que hemos sufrido" $y$ en donde no se ha "dejado de depender de la creación científica y técnica del extranjero". (p. 9)

Esta dependencia en el uso de términos administrativos ha generado en este campo la utilización de palabras de otros idiomas para referirse a vocablos que son claramente identificados en el idioma español como gestión o management, como sinónimo de administración, o marketing como sustituto de mercadotecnia; esto ha contribuido a generar cierta confusión en el uso de los términos, no solo en la teoría sino también en la práctica administrativa. Asimismo, esta dependencia terminológica también ha provocado malas traducciones y falta de rigor para entender el contexto en el que se utilizan. Si el lenguaje administrativo carece de solidez conceptual, como se ha señalado, esta dependencia provoca una mayor confusión en la comprensión de conceptos administrativos.

$* * *$

8 Lara, haciendo alusión al vocabulario cinematográfico, que bien se puede equiparar con el de la administración, señala que "[...] el interés por un vocabulario especializado como el que contiene este diccionario sigue siendo algo marginal, que escasamente ocupa a unos cuantos lexicógrafos. Las obras de consulta que pueden encontrarse, cuando las hay, suelen ser pocas y muchas veces inadecuadas para una cultura como la mexicana, porque han sido elaboradas en otros ámbitos de la comunidad hispanohablante y sin consideración de la variedad que caracteriza a nuestra lengua española". (1994, p. 9) 


\section{Referencias bibliográficas}

1. Aktouf, O. (2009). La administración: entre tradición y renovación (4. ${ }^{a}$ ed.). Universidad del Valle - Universidad Libre.

2. Barnard, Ch. (1960). The Functions of the Executive. Harvard University Press.

3. Barnard, Ch. (1988). Prólogo a la primera edición norteamericana. En Herbert Simon. El comportamiento administrativo. Estudio de los procesos de adopción de decisiones en la organización administrativa (pp. XXXIX-XLI). Aguilar.

4. Benveniste, É. (1987). Problemas de lingüística general. Siglo XXI.

5. Dávila L. de G., C. (1985). Teorías organizacionales y administración: enfoque crítico (1. ${ }^{\text {a }}$ ed.). McGraw Hill.

6. Fayol, H. (1971). Administración industrialy general (1. a ed. Esp.). Herrero Hermanos.

7. Gulick, L., Urwick, L., Mooney, J., Fayol, H., Dennison H., Henderson, L., Whitehead, T., Mayo, E., Parker F., M., Lee, J. y Graicunas, V. (1970). Ensayos sobre la ciencia de la administración. ICAP.

8. Gutiérrez R., B. (1998). La ciencia empieza en la palabra. Análisis e historia del lenguaje científico. Península.

9. Julián P., M. (1997). Importancia de la elaboración de un catálogo de diccionarios de las disciplinas financiero-administrativas. Revista Contaduría y Administración, (185), 69-76.

10. Kliksberg, B. (1990). El pensamiento organizativo: de los dogmas a un nuevo paradigma gerencial. Editorial Tesis.

11. Koontz, H., O'Donnell, C. y Heinz, W. (1988). Administración (8. a ed.). McGraw Hill.

12. Koontz, H. (1999). La jungla de la teoría administrativa. Contaduría y Administración, (193), 37-52.

13. Koontz, H. (2000). Revisión de la jungla de la teoría administrativa. Revista de Contaduría y Administración, (199), 55-74.

14. Lara, L.F. (1994). Prólogo. En Cardero, A. M. Diccionario de términos cinematográficos usados en México. Universidad Nacional Autónoma de México.

15. Lara, L. F. (2006). Curso de lexicología. Colegio de México.

16. Minztberg, H. (1991). Minztberg y la dirección. Ediciones Díaz de Santos.

17. Ríos S., J. (2011). Contribución al estudio de la naturaleza y problemática fundamental del lenguaje teórico organizacional. [Tesis Doctoral, Universidad Nacional Autónoma de México]. Archivo digital. http://132.248.9.195/ptb2011/ julio/0670916/0670916_A1.pdf 
18. Simon, H. (1988). El comportamiento administrativo. Estudio de los procesos de adopción de decisiones en la organización administrativa. Aguilar.

19. Terry, G. (1982). Principios de administración. CECSA.

\begin{tabular}{|c|l|}
\hline $\begin{array}{c}\text { Para citar } \\
\text { este artículo: }\end{array}$ & $\begin{array}{l}\text { Cruz S., L. A. y Julián P., M. (2021). La terminología en administración. Teuken } \\
\text { Bidikay, 12(18). 25-44. doi: 10.33571/teuken.v12n18a1 }\end{array}$ \\
\hline
\end{tabular}

Ge*: AMV.

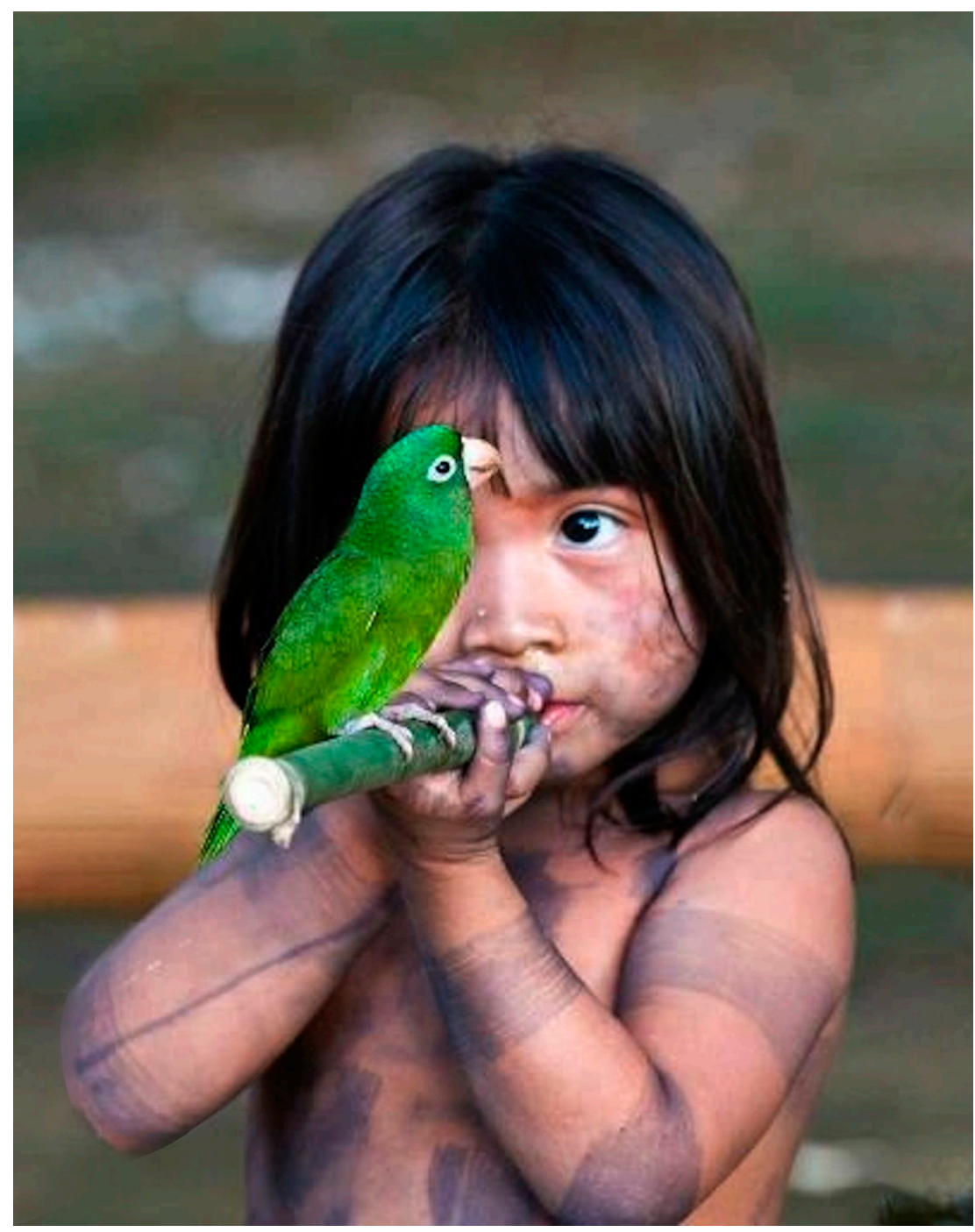

